\title{
Determining Causation from Observational Studies: A Challenge for Modern Neuroepidemiology
}

\author{
George A. Jelinek* \\ University of Melbourne, Melbourne, VIC, Australia
}

Keywords: Mendelian randomization analysis, neuroepidemiology, specialty grand challenge, multiple sclerosis, randomized control trials, vitamin $D$, lifestyle risk factors

\section{BACKGROUND}

While epidemiology is the study of frequencies, trends, and determinants of disease in specified populations, the overriding aim of epidemiology is to apply such knowledge to prevention. Both primary and secondary prevention benefit from a detailed understanding of risk factors that can be uncovered through careful epidemiological research. Clearly some factors associated with outcomes in cross-sectional studies may be risk factors, but also may not, and indeed may not be in longitudinal studies. While risk factors are causal, some are modifiable and some not. But some risk factors that we have long regarded as fixed and not modifiable, such as genetics, have more recently, in the exploding science of epigenetics, been shown to be more or less expressed through different lifestyles. Ornish et al. has shown for example that intensive lifestyle changes favorably modulate gene expression in prostate cancer (1) and, with Nobel laureate Elizabeth Blackburn, that such environmental factors can reverse what was thought to be an inevitable decline in telomere length associated with aging and disease (2).

Edited and Reviewed by: Jose Biller, Loyola University Chicago, United States

*Correspondence: George A. Jelinek george.jelinek2@gmail.com

Specialty section: This article was submitted to Neuroepidemiology, a section of the journal Frontiers in Neurology

Received: 08 May 2017 Accepted: 24 May 2017 Published: 01 June 2017

Citation:

Jelinek GA (2017) Determining

Causation from Observational Studies: A Challenge for Modern Neuroepidemiology.

Front. Neurol. 8:265. doi: 10.3389/fneur.2017.00265

\section{NEWER TECHNIQUES IN NEUROEPIDEMIOLOGY}

Comprehensive analysis of modifiable risk factors through epidemiological studies paves the way for translation into appropriate intervention studies. But such studies are difficult. However, new techniques in observational epidemiology are now transforming our capacity to infer causality and may well offer some advantages over conventional randomized controlled trials (RCTs). New analytic approaches enable us to better account for biases including selection, confounding, and information bias. While longitudinal cohort studies have traditionally allowed stronger inferences than cross-sectional studies, more recent techniques such as instrumental variable analysis, which better accounts for confounding and reverse causation, offer great potential to improve causal inference. Key assumptions of instrumental variable analysis are that the instrument is only related to the outcome through the exposure (or risk factor) and that there are no direct paths between the instrument and confounders. Genetic polymorphisms are excellent examples of instrumental variables in epidemiological studies since they are "randomly assigned" and have been used in a range of studies of lifestyle risk factors such as obesity. The use of genetic variants as instruments is referred to as Mendelian randomization (3).

\section{THE EXAMPLE OF MULTIPLE SCLEROSIS (MS)}

Let us take MS as an example. MS is thought to be an autoimmune inflammatory demyelinating disease of the central nervous system. The genetic predisposition to MS accounts for around $24 \%$ of the 
risk of developing the disease (4), and the likely environmental risk factors have been well known for many years, elucidated through epidemiological research. Those factors about which there is a reasonable degree of agreement include low vitamin D levels (5) and lack of sunlight exposure (6), cigarette smoking (7), low omega 3 fatty acid intake (8) and poor blood lipid profile (9), lack of exercise (10), and obesity (11). While findings have generally been consistent with respect to these risk factors, many studies have not adequately accounted for confounding or reverse causation.

While some or all of these factors are likely to be causally related to disease development, for many years, it was thought that there was little environmental influence on progression. However, recent genome-wide studies in people with MS have shown that genetics plays little role in disease progression to disability (12). This has prompted renewed search for modifiable lifestyle risk factors that may accelerate disability progression with the aim of allowing a comprehensive secondary prevention program to be developed for people with the illness. It is biologically plausible that some or most of the environmental risk factors for progression would be the same as those that precipitate the disease in the first place; studies conducted over many decades now have pointed the finger at animal fats and poor fruit and vegetable intake in the diet $(13,14)$, poor blood lipid profile $(15)$, low omega 3 fatty acid intake $(13,16)$, obesity $(9)$, low vitamin D levels (17), lack of sun exposure (18), cigarette smoking $(17,19)$, low levels of exercise (20), and stress (21).

\section{OBSERVATIONAL VERSUS INTERVENTION DATA}

The problem for researchers is how and indeed whether it is feasible to proceed beyond observational to intervention data, given that the majority of interventions based on these data require significant lifestyle change by research participants. It is at least arguable that more sophisticated epidemiological techniques may make this requirement moot. The example of Mendelian randomization in proving the effect of low blood vitamin D levels in causing MS is illustrative. Richards' group from McGill University's Department of Epidemiology elegantly applied genome-wide data on genetic variants that predicted blood vitamin D levels from the Canadian Multicentre Osteoporosis Study to participants in the International MS Genetics Consortium study (22). They found that a genetic decrease in blood vitamin D level predicted increased MS susceptibility, effectively meaning that a $50 \%$ increase in blood level decreased the odds of getting MS by $50 \%$.

This sophisticated research largely removed the possibility of confounding or reverse causation. While some may undervalue this evidence because it is observational, it actually has important advantages over RCTs, long considered the research gold standard. Mendelian randomization techniques allow for the lifetime exposure to vitamin D-lowering genes in the population, whereas RCTs are by necessity shorter and generally on smaller populations. Richards' study provides strong evidence of causation, as did their later study on genetically determined obesity and MS risk (11), and backs up prospective observational studies such as the US Nurses Health Study that showed significantly reduced risk of developing MS with relatively low doses of vitamin D supplementation (23). What is needed is a similar focus, through similar methodology, on the association, for example, of this genetically determined propensity to obesity with disease progression. Arguably, such epidemiological studies could provide more robust evidence than intervention studies, given their limitations. This is possible for a range of neurological diseases with significant lifestyle determinants.

\section{PROBLEMS WITH RCTS}

Randomized controlled trials of disease-modifying drugs (DMDs) in MS are relatively simple to perform and have contributed to major therapeutic advances in MS management. While there are some limitations around blinding related to side effects, randomization is relatively simple and adherence is not the difficult issue for DMD research that it is in lifestyle risk factor modification studies. Take diet for example, which is probably one of the most studied but most controversial of risk factors for MS progression. Since the uncontrolled intervention study of Swank and Dugan over an extraordinarily long timeframe showed that "poor dieters" had much worse outcomes than those who could dramatically reduce animal fat in their diets (24), numerous epidemiological studies (25) and a few very small RCTs $(26,27)$ have provided evidence about animal fat being a key risk in MS disease progression, along with resultant poor blood lipid profile $(15,28,29)$ and overweight and obesity $(11,30)$.

However, RCTs that test these interventions are difficult to conduct and have significant limitations (31). First, loss to follow-up is an important issue, particularly loss of participants with more severe disease or more rapid disease progression. This tends to exaggerate treatment effects in those who remain to study conclusion. Second, lack of adherence to the study treatment is an obvious limitation in determining causal effects of treatment. While an "as treated" analysis can be useful, it introduces bias, and intention-to-treat ("as allocated") analysis is usually preferred, despite its inherent underestimation of causal treatment effect. Finally, unblinding, which is unavoidable in complex interventions where the goal is behavior change, encourages behavior change outside of the prescribed intervention, with unpredictable effects of treatment effect estimation depending on what behaviors change and in which group.

\section{A CHALLENGE FOR NEUROEPIDEMIOLOGY}

Given these and other limitations of RCTs in this area, the challenge for modern neuroepidemiology is to further develop techniques that allow strong causal inferences to be drawn from more sophisticated longitudinal observational research to allow the framing of robust secondary preventive recommendations for people with potentially devastating neurological illnesses. The risks of waiting for RCTs to "prove" the case for risk factor modification-based secondary prevention are obvious. 


\section{AUTHOR CONTRIBUTIONS}

The author confirms being the sole contributor of this work and approved it for publication.

\section{REFERENCES}

1. Ornish D, Magbanua MJ, Weidner G, Weinberg V, Kemp C, Green C, et al. Changes in prostate gene expression in men undergoing an intensive nutrition and lifestyle intervention. Proc Natl Acad Sci U S A (2008) 105(24):8369-74. doi:10.1073/pnas.0803080105

2. Ornish D, Lin J, Chan JM, Epel E, Kemp C, Weidner G, et al. Effect of comprehensive lifestyle changes on telomerase activity and telomere length in men with biopsy-proven low-risk prostate cancer: 5-year follow-up of a descriptive pilot study. Lancet Oncol (2013) 14(11):1112-20. doi:10.1016/ S1470-2045(13)70366-8

3. Davey Smith G, Ebrahim S. What can Mendelian randomisation tell us about modifiable behavioural and environmental exposures? BMJ (2005) 330(7499):1076-9. doi:10.1136/bmj.330.7499.1076

4. Sadovnick AD, Ebers GC, Dyment DA, Risch NJ. Evidence for genetic basis of multiple sclerosis. The Canadian Collaborative Study Group. Lancet (1996) 347(9017):1728-30. doi:10.1016/S0140-6736(96)90807-7

5. Rhead B, Baarnhielm M, Gianfrancesco M, Mok A, Shao X, Quach H, et al. Mendelian randomization shows a causal effect of low vitamin D on multiple sclerosis risk. Neurol Genet (2016) 2(5):e97. doi:10.1212/ NXG.0000000000000097

6. Lucas RM, Ponsonby AL, Dear K, Valery PC, Pender MP, Taylor BV, et al. Sun exposure and vitamin D are independent risk factors for CNS demyelination. Neurology (2011) 76(6):540-8. doi:10.1212/WNL.0b013e31820af93d

7. Backhaus I, Mannocci A, Lemmens PH, La Torre G. Smoking as a risk factor for developing multiple sclerosis: a meta-analysis of observational studies. Clin Ter (2016) 167(3):82-92. doi:10.7417/CT.2016.1932

8. Bjornevik K, Chitnis T, Ascherio A, Munger KL. Polyunsaturated fatty acids and the risk of multiple sclerosis. Mult Scler (2017):1352458517691150. doi:10.1177/1352458517691150

9. Tettey P, Simpson S, Taylor B, Ponsonby AL, Lucas RM, Dwyer T, et al. An adverse lipid profile and increased levels of adiposity significantly predict clinical course after a first demyelinating event. J Neurol Neurosurg Psychiatry (2017) 88(5):395-401. doi:10.1136/jnnp-2016-315037

10. Wesnes K, Myhr KM, Riise T, Cortese M, Pugliatti M, Bostrom I, et al. Physical activity is associated with a decreased multiple sclerosis risk: the EnvIMS study. Mult Scler (2017):1352458517694088. doi: $10.1177 / 1352458517694088$

11. Mokry LE, Ross S, Timpson NJ, Sawcer S, Davey Smith G, Richards JB. Obesity and multiple sclerosis: a Mendelian randomization study. PLoS Med (2016) 13(6):e1002053. doi:10.1371/journal.pmed.1002053

12. SawcerS, HellenthalG, Pirinen M,SpencerCC, Patsopoulos NA, MoutsianasL, et al. Genetic risk and a primary role for cell-mediated immune mechanisms in multiple sclerosis. Nature (2011) 476(7359):214-9. doi:10.1038/ nature 10251

13. Esparza ML, Sasaki S, Kesteloot H. Nutrition, latitude, and multiple sclerosis mortality: an ecologic study. Am J Epidemiol (1995) 142(7):733-7.

14. Hadgkiss EJ, Jelinek GA, Weiland TJ, Pereira NG, Marck CH, van der Meer DM. The association of diet with quality of life, disability, and relapse rate in an international sample of people with multiple sclerosis. Nutr Neurosci (2015) 18(3):125-36. doi:10.1179/1476830514Y.0000000117

15. Tettey P, Simpson S Jr., Taylor B, Blizzard L, Ponsonby AL, Dwyer T, et al. An adverse lipid profile is associated with disability and progression in disability, in people with MS. Mult Scler (2014) 20(13):1737-44. doi:10.1177/1352458514533162

16. Jelinek GA, De Livera AM, Marck CH, Brown CR, Neate SL, Taylor KL, et al. Associations of lifestyle, medication, and socio-demographic factors with disability in people with multiple sclerosis: an international cross-sectional study. PLoS One (2016) 11(8):e0161701. doi:10.1371/journal.pone.0161701

\section{ACKNOWLEDGMENTS}

I thank Professor Anne Kavanagh for her continuing guidance and support and her careful review and comments on the manuscript.

17. Hempel S, Graham GD, Fu N, Estrada E, Chen AY, Miake-Lye I, et al. A systematic review of modifiable risk factors in the progression of multiple sclerosis. Mult Scler (2017) 23(4):525-33. doi:10.1177/1352458517 690270

18. Lucas RM, Byrne SN, Correale J, Ilschner S, Hart PH. Ultraviolet radiation, vitamin D and multiple sclerosis. Neurodegener Dis Manag (2015) 5(5):413-24. doi: $10.2217 / \mathrm{nmt} .15 .33$

19. Tanasescu R, Constantinescu CS, Tench CR, Manouchehrinia A. Smoking cessation and the reduction of disability progression in multiple sclerosis: a cohort study. Nicotine Tob Res (2017). doi:10.1093/ntr/ntx084

20. Motl RW, Pilutti LA. Is physical exercise a multiple sclerosis disease modifying treatment? Expert Rev Neurother (2016) 16(8):951-60. doi:10.1080/14737175. 2016.1193008

21. Lovera J, Reza T. Stress in multiple sclerosis: review of new developments and future directions. Curr Neurol Neurosci Rep (2013) 13(11):398. doi:10.1007/ s11910-013-0398-4

22. Mokry LE, Ross S, Ahmad OS, Forgetta V, Smith GD, Goltzman D, et al. Vitamin D and risk of multiple sclerosis: a Mendelian randomization study. PLoS Med (2015) 12(8):e1001866. doi:10.1371/journal.pmed.1001866

23. Munger KL, Zhang SM, O’Reilly E, Hernan MA, Olek MJ, Willett WC, et al. Vitamin D intake and incidence of multiple sclerosis. Neurology (2004) 62(1):60-5. doi:10.1212/01.WNL.0000101723.79681.38

24. Swank RL, Dugan BB. Effect of low saturated fat diet in early and late cases of multiple sclerosis. Lancet (1990) 336(8706):37-9. doi:10.1016/0140-6736(90)91533-G

25. Jelinek G. Overcoming Multiple Sclerosis: The Evidence-Based 7 Step Recovery Program. Sydney: Allen and Unwin (2016).

26. Weinstock-Guttman B, Baier M, Park Y, Feichter J, Lee-Kwen P, Gallagher E, et al. Low fat dietary intervention with omega-3 fatty acid supplementation in multiple sclerosis patients. Prostaglandins Leukot Essent Fatty Acids (2005) 73(5):397-404. doi:10.1016/j.plefa.2005.05.024

27. Yadav V, Marracci G, Kim E, Spain R, Cameron M, Overs S, et al. Low-fat, plant-based diet in multiple sclerosis: a randomized controlled trial. Mult Scler Relat Disord (2016) 9:80-90. doi:10.1016/j.msard.2016.07.001

28. Weinstock-Guttman B, Zivadinov R, Horakova D, Havrdova E, Qu J, Shyh G, et al. Lipid profiles are associated with lesion formation over 24 months in interferon-beta treated patients following the first demyelinating event. J Neurol Neurosurg Psychiatry (2013) 84(11):1186-91. doi:10.1136/ jnnp-2012-304740

29. Weinstock-Guttman B, Zivadinov R, Mahfooz N, Carl E, Drake A, Schneider J, et al. Serum lipid profiles are associated with disability and MRI outcomes in multiple sclerosis. J Neuroinflammation (2011) 8:127. doi:10.1186/1742-2094-8-127

30. Tettey P, Siejka D, Simpson S Jr., Taylor B, Blizzard L, Ponsonby AL, et al. Frequency of comorbidities and their association with clinical disability and relapse in multiple sclerosis. Neuroepidemiology (2016) 46(2):106-13. doi:10.1159/000442203

31. Hernan MA. A definition of causal effect for epidemiological research. J Epidemiol Community Health (2004) 58(4):265-71. doi:10.1136/jech. 2002.006361

Conflict of Interest Statement: The author receives royalties from his book Overcoming Multiple Sclerosis: The Evidence-Based 7 Step Recovery Program.

Copyright (ㄷ) 2017 Jelinek. This is an open-access article distributed under the terms of the Creative Commons Attribution License (CC BY). The use, distribution or reproduction in other forums is permitted, provided the original author(s) or licensor are credited and that the original publication in this journal is cited, in accordance with accepted academic practice. No use, distribution or reproduction is permitted which does not comply with these terms. 